Visualizing Objects, Places, and Spaces: A Digital Project Handbook

\title{
Collaborate with Andalusia and America
}

Maurizio Toscano, Yolanda Guasch

Published on: Feb 14, 2021

License: Creative Commons Attribution 4.0 International License (CC-BY 4.0). 


\section{Team}

The research group is led by Rafael López Guzmán, Full Professor of History of Art at the University of Granada, Spain. Yolanda Guasch Marí and María Dolores Caparros Masegosa are in charge of records revision and control. Other members of the research group are continuously involved in data collection and data entry. In particular, Adrián Contreras and Guadalupe Romero are in charge of artworks records from South America. Ana Ruiz Gutiérrez y Gloria Espinosa are in charge of Northern and Central America, plus Caribe.

Maurizio Toscano has assisted the research group in the project design since the beginning and is in charge of the development and maintenance of the web platform.

\section{Project URLs}

Online platform: https://colabora.andaluciayamerica.com

Research project website: https://candaluciayamerica.com

Research paper describing the platform:

https://revistaquiroga.andaluciayamerica.com/index.php/quiroga/article/viewFile/252/207

\section{Project Abstract}

The interactive Web platform Collaborate with Andalucía and America has been conceived as a collaborative initiative, involving History of Art researchers and members of the public, to extend and improve a catalogue of artworks created by Andalusian artists in Latin America. The initiative has been promoted by the research group "Andalucía-América: Patrimonio cultural y relaciones artísticas", affiliated to the University of Granada, Spain, in collaboration with Digital Humanities specialists. 


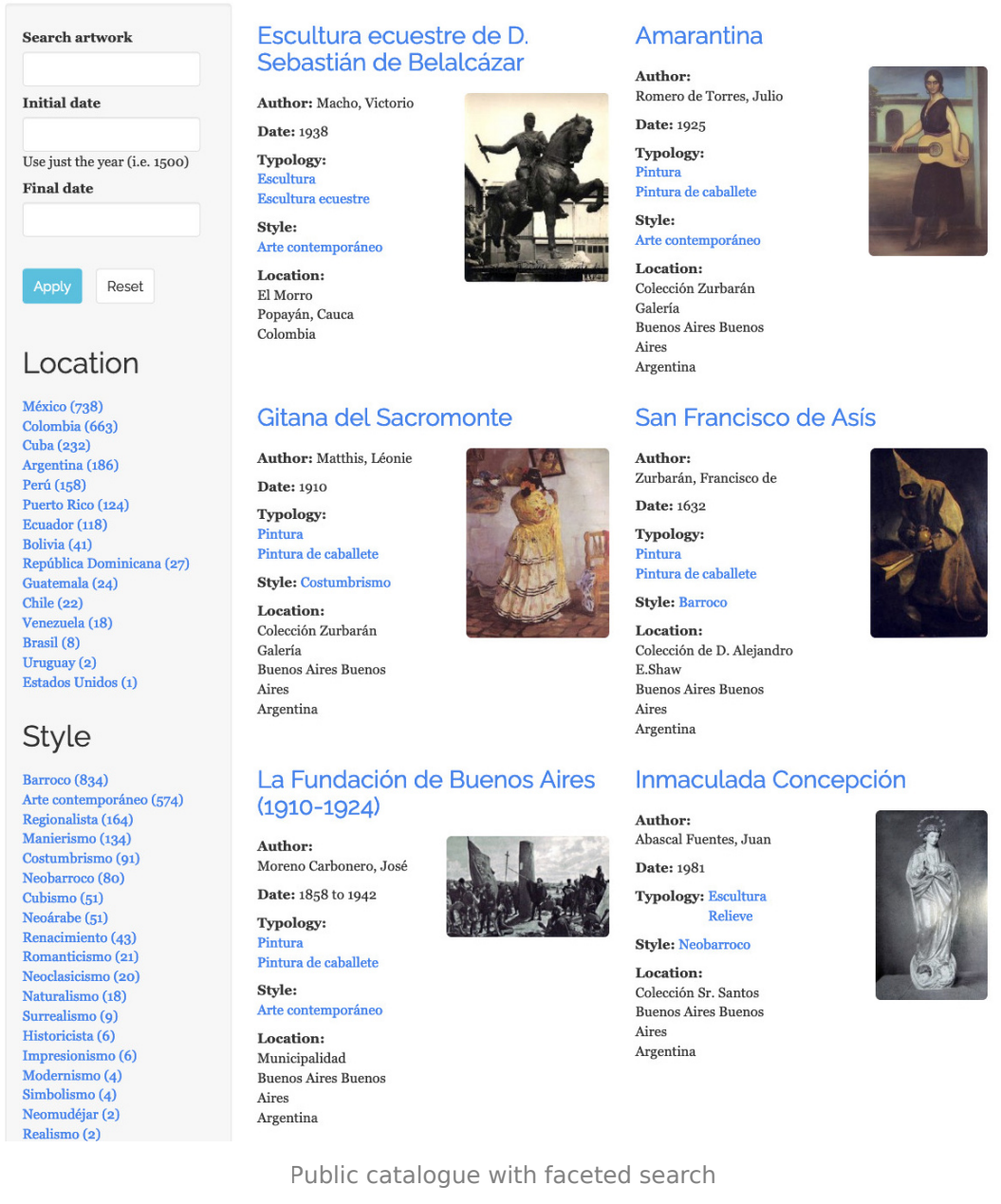

The digital catalogue initially published online, for public consultation, around 2600 records collected during several successive research projects on this topic. The aim was to create a means of broadening and improving the existing dataset at a global level. Taking advantage of the Internet, it is now possible to gather contributions directly from the study areas or from other research groups that are working on related topics. 


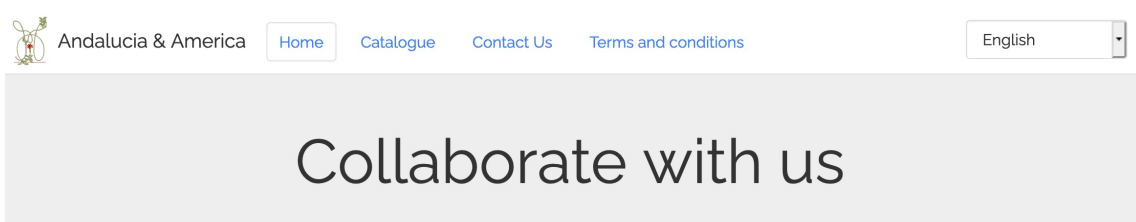

Navigation

Record new artwork

Artworks you already recorded

User menu

My account

Log out
Thank you for collaborating with us!

Use the link to the left to register a artwork Andalusian artists in Latin America.

To make your participation more valuable, we encourage you to check before our catalog of recorded artworks to avoid

creating duplicate records.

At the same time you can help us improving the catalogue, sending new information or better photos of the artworks.

We are aware of the importance and impulse that Digital Humanities are having, so we incorporate a catalogue with the most relevant results achieved in previous projects. We open up the project to all the researchers, academics and society, that want to work with us and give us information about artists, works of art, patrons or iconography in South America. The online catalogue it's a part of "Artistic patrimony and relationships between Andalusia and South America" project (HAR2014-57354-P), funded by The Ministry of Economy of Spanish Government.

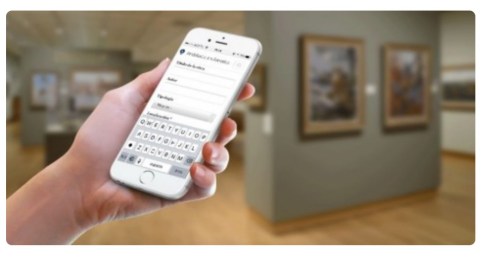

Logged user welcome screen

\section{Record Artwork}

\section{Navigation \\ Record new artwork}

Artworks you already recorded

User menu

My account

Log out

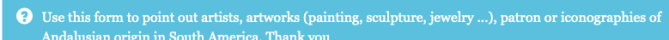

Andalucian origin in South America. Thank yo

Artwork title

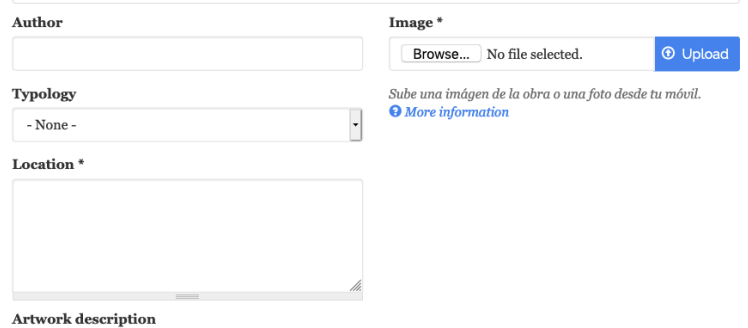

Artwork deseriptio

How did you find this artwork

Por ejemplo porque eonoces el autor, durante una visita a un museo, porque tienes un catalogo en casa etc.

Accept Terms and Conditions *

Read terms and conditions

\section{$\checkmark$ Save}

External collaborators data entry form. 
Later on, the catalogue's range of functionalities expanded to become the centralized working environment of the research group promoting the initiative. Since the initial publication, the catalogue grew considerable, counting now 4254 records, many of which are still in the private revision phase.

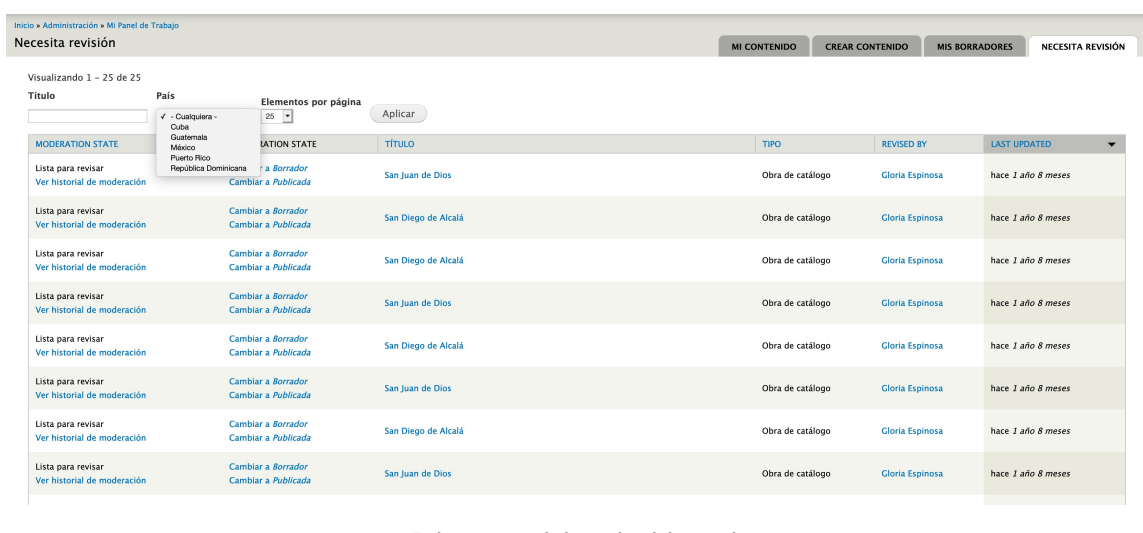

Private revision dashboard

\section{Time Needed}

When did you begin this project? When did you complete this project?

Initial development: 5 months.

Project Time Span: November 10, 2015 - ongoing.

Length: $5+$ years.

\section{Outcomes}

What is the outcome of the project?

The main results from the project are the public website, the private virtual research environment (VRE) and a research paper describing the platform.

\section{Resources}

What tools, resources, programs, or equipment did you use for this project? 
The digital platform was built using the Drupal CMS, version 7, known for its large and active community of users/developers and a wide variety of modules that cover many needs. Drupal has been widely used for DH project, especially those communities-oriented, and it served us well in several other projects (www.historicgraves.com; www.exiliadosrepublicanos.info; virtual3dugr.prehistoriayarqueologia.org). Some modules were modified in order to accomplish the required functionalities, but the vast majority was used as it. Major modules used include, among others:

- Search API + Facet API (for faceted search);

- Feed (to import existing data);

- Address field + Location taxonomize (to maintain the Location Vocabulary);

- Workbench Moderation (for submission and revision workflow).

\section{Funding}

Please describe any costs incurred for this project, and (if relevant) how you secured funding for these costs.

The first batch of artworks was collected during the research project "Andalucía en América. Arte, cultura y sincretismo estético" (P07-HUM-03052), financed by the Junta de Andalucía.

The first version of the web platform (2015-2016) was funded as part of the research project "Artistic patrimony and relationships between Andalusia and South America" (HAR2014-57354-P), financed by the Ministry of Economy of Spanish Government.

The second phase (2018-2019), that added private functionalities for the research group (draft mode, multi-authors records, review workflow, ...), was funded as part of the research project "Artistic relations between Andalusia and America. The peripheral territories: United States and Brazil" (HAR2017-83545-P), financed by the Ministry of University and Research of Spanish Government.

\section{Workflow}

Please give an overview of the workflow or process you followed to execute this project, including time estimates where possible.

Since 2008, we have collected approximately 2,600 records of artworks created by Andalusian artists throughout twelve Latin American countries, dating from the Renaissance to the present. The records include detailed information about the artist, style, iconography, chronology, and location, with the latter organized from the country down to the building level. Existing data, stored until 2015 in a local 
Microsoft Access database, has been migrated to MySQL to provide online concurrent access. The dataset has been published as individual records, presented in a catalogue view, with an advanced faceted search engine. Registered users have two options to collaborate: improving existing records or reporting a new artwork.

It took approximately 5 months to complete the first phase of the project, from conception to online publishing.

In the last three years a new phase of intensive data entry has been carried out, bringing the total amount of records to 4254, many of which are currently under review.

\section{Challenges \& Opportunities}

What, if anything, changed between beginning your project and its current/final form?

As said, the project started as an initiative to involve civil society in improving and extending the existing catalogue. Later on, the research group realized the potential of having a centralized online database and opted for a phase two with improved functionalities accessible only to users with certain roles, and a more elaborate publishing workflow.

Is there anything specific you wish you had known when beginning your project that might help other people to know?

- Spending more time in the planning phase, even if everything looks already planned, can save you time later on. For example, having planned from the beginning the use of the platform as a internal workspace for the research group, as well as a public catalogue, could have improved initial data modelling.

- The importance of engagement throughout the project lifetime, with strategies targeted to different groups.

- The effectiveness of Open Access publishing, which we tested thanks to feedback received after publishing the article describing the platform, cited below.

\section{Next Steps}

Do you have any plans to follow up on this project or work on something similar in the future? 
The project is currently focused on expanding the existing dataset to peripheral territories, mainly the United States and Brazil, in line with the objectives of the second funded phase. From the point of view of the platform, there are plans to implement semantic markup to improve and interoperability. Considering that Drupal 7 official support has been extended to November 2022, next summer (2022) we plan to study upgrading the platform to Drupal 9 or BackdropCMS.

\section{Publications \& Presentations}

Toscano, Maurizio. “Andalucía y América. Plataforma Colaborativa sobre Patrimonio Artístico Iberoamericano." Quiroga 14. July-December 2018: 36-43. 